\section{A Live Experiences on Quality of Life Among HIV Positive Patients}

\section{Abstract}

Back ground: Many people living with HIV/AIDS are finding it difficult to attend their daily tasks of living. Hence the present study is an attempt to assess their live experiences on quality of life.

Methods: We used phenomenological research design. Through purposive sampling technique data was collected on live experiences of quality of life among 12 HIV positive patients through in-depth interview from two focus groups, one involving male patients with HIV positive and another female patients HIV positive. Then the collected data was analyzed thematically.

Results: From the study, themes identified were sources of HIV transmission, reaction to HIV diagnosis, impact of HIV on family members, disclosure of HIV, impact of HIV infection in daily life and stigma among health care workers.

Conclusion: Study concluded that patients living with HIV positive are finding difficult lead a life in day to day activities.

Keywords: HIV/AIDS; Quality of life; HIV positive patients

\section{Lakshmi V* \\ Sri Devaraj URS College of Nursing, Kolar, Karnataka, India}

\author{
*Corresponding author: Dr. Vijaya Lakshmi \\ ¡ lakshmi_vijaya_venkatesh@yahoo. \\ co.in
}

Sri Devaraj URS College of Nursing, Kolar, Karnataka, India.

Tel: 08152649209

Citation: Lakshmi V. A Live Experiences on Quality of Life Among HIV Positive Patients. Insights Biomed. 2017, 2:2.

Received: May 18, 2017; Accepted: June 24, 2017; Published: June 27, 2017

\section{Introduction}

Quality of life (QOL) is the term that is popularly used to convey an overall sense of well-being and it includes aspects such as happiness and satisfaction with life as a whole. World Health Organization has defined QOL as "individuals" perceptions of their position in life in the context of the culture and value systems in which they live and in relation to their goals, standards, expectations and concerns" [1]. With the recent advances in clinical tests and treatments for those suffering from human immunodeficiency virus (HIV)/acquired immunodeficiency syndrome (AIDS), the survival of these patients has been increased and their QOL has become an important focus for researchers and healthcare providers [2]. Since the discovery, HIV/AIDS has been one of the greatest health problems in the world [3] and it places an increasing burden on the health of the population, and causes further socioeconomic problems for individuals, families, communities, and governments in many countries [4,5].

HIV is considered as a chronic disease. This means a person living with HIV, has to cope with a range of HIV-related symptoms for extended periods. These symptoms may be related to the infection itself or comorbid illnesses, or iatrogenic effects from HIV-related medications [6,7]. Many of the HIV patients struggle with numerous social problems such as stigma, poverty, depression, substance abuse, and cultural beliefs, which can affect their QOL not only from the physical health aspect, but also from mental and social health point of view and cause numerous problems in useful activities and interests of the patients [8]. Assessing health-related quality of life (HRQOL) is useful for documenting the patients' perceived burden of chronic disease, tracking changes in health over time, assessing the effects of treatment and quantifying the return on health care investment [9]. Hence the researcher felt to know the live experiences of HIV positive patients with an objective to assess the quality of life in their own words.

\section{Materials and Methods}

The research design used for the study was phenomenological research design. First an ethical permission was obtained from Institutional ethical committee and then a written permission was obtained from Co-coordinator of Samagra Community Health Centre, SNR hospital, Kolar, which is a voluntary organization. For the study, around 12 (06 males and 06 females) HIV positive patients who were between the age group of 18 years to 60 years, able to communicate in Kannada or English and willing to participate in the study were included. Through purposive 
sampling technique two focus groups were made separately for males and females. Then researcher facilitated the groups with her assistants. The tool consisted of two sections. Section-A had eight variables and section-B has six open-ended questions. The researcher collected data on 13 February 2013. First sociodemographic variables followed by live experiences of HIV positive patient's data were collected.

\section{Data analysis}

Data analysis was done immediately, by debriefing after each focus group discussion and by listening to the sound recording and verifying the data (taken by the researcher and assistants). The whole content was verified by reading line by line and paragraph by paragraph, looking for significant statements and codes according to the topics addressed. The researcher used three levels of coding.

In the level one coding researcher examine the data line by line and making codes which were taken from the language of the subjects who attended the focus group. In level two coding, comparing of coded data with other data and creation of categories were done. In level three coding, the categories that seem to cluster together were formed as themes. Then the documents were submitted to experts for validation. This action provided an opportunity to determine the reliability of the coding.

\section{Results}

\section{Socio-demographic variables}

A total of 12 HIV positive patients were studied in the present study. (Table 1 ) displays majority (41.66\%) of HIV positive patients participated in the study were between 35 years to 44 years of age group, $50 \%$ of them were males and $50 \%$ of them were females, most $(91.7 \%)$ of them were Hindus, $91.7 \%$ of them were married, in that $66.7 \%$ of them were having children, majority (58.3\%) were illiterates and $66 \%$ of them were depending on their spouse for their source of income.

\section{Quality of life among HIV positive patients}

Regarding quality of life, from analysis six themes were identified and presented as follows.

THEME-1: Source of HIV transmission: All participants expressed that the source of transmission of HIV infection was their spouses.

One female participant said that;

Table 1 Socio-demographic variables of HIV positive patients ( $\mathrm{N}=12$ ).

\begin{tabular}{|c|c|}
\hline Variables & HIV positive Patients \\
\hline Age (yrs) & $41.66 \%$ (35-44 yrs) \\
\hline Males & $50 \%$ \\
\hline Females & $50 \%$ \\
\hline Hindus & $91.7 \%$ \\
\hline Married & $91.7 \%$ \\
\hline Having children & $66.7 \%$ \\
\hline Illiterates & $58.3 \%$ \\
\hline Depends on spouse for source Income & $66 \%$ \\
\hline
\end{tabular}

"I have got HIV from my husband. He had bangle business. He traveled from one village to another village, then he got HIV and through him, I got HIV".

Another male patient expressed that;

"My wife was more socialized as she used to visit women's group daily, from her I got HIV but she expired due to HIV"

One more patient added to this;

"I was a stone cutter and used to travel from one place to another for my job and I had the habit of going with females, hence I got HIV".

THEME-2: Reaction to HIV diagnosis: Most of HIV positive patients reported that they have experienced a feeling of shock, fear of others is aware of their HIV status.

One female patient said that;

"When I heard that I got HIV, I was shocked, unable to express and felt how to face others"

Another female patient added to this;

"When I heard, I got HIV, I felt very bad, felt like to die and also thought who will take care of my children?"

One male patient said that;

"When I heard that I got HIV, I thought it's my fate, what can I do? I felt I should learn to live with this."

THEME-3: Impact of HIV on family members: Majority (80\%) of HIV positive patients expressed that their family members take care of them very well with love and affection.

One female patient said that,

"My husband (who is also HIV positive) takes care of me very well with love and care than before."

Another male patient added to this;

"As my wife also got HIV, there is no difference in love and care in the present compared to the past."

THEME-4: Disclosure of HIV: Some participants said that disclosure of the disease was a very sensitive issue. Some of them thought that disclosure to their children and parents might discriminate against them, the information would affect their studies and parents cannot move freely with the society.

One patient said that;

"I am unmarried, I have not told my mother about my disease because she might feel bad to know that I am suffering with HIV and my family members may keep me away from home."

All HIV positive women patients showed their concern about children.

\section{One patient said that;}

"My children are studying in professional college if I say to them, what will be their reaction? If they accept me, it will be fine but if they don't accept and reject me? So, I am very scared to inform them". 
THEME-5: Impact of HIV infection in daily life: All patients accepted that taking anti-retroviral treatment regularly with intake of adequate balanced diet without worrying may improve their health status.

Most of the female patients expressed that they were unable to get sufficient food.

One patient said that;

"I used to go for coolie, now I have admitted and taking treatment. This induces too much hunger. Hospital provides two meals and one breakfast which are not going to be sufficient for me.

Almost all male patients expressed that they would like to work for their food, but no one gives job nor they were able to work like earlier.

One patient said that;

"When I was going out for job earlier, I used to earn Rs 10,000/per month but know not even Rs 10/- per month. Because of the disease and treatment, I feel excessive hunger, I am unable to take care of me and the family. Government should plan some job for such family like me."

Another patient added to this;

"When I go out for haunting a job locally, no one gives me. So, I required travel from one place to another. While travelling, because of my ill health, I feel as if I am going to die on the way itself."

One more patient added to this;

"Our condition is so pathetic means we are unable to earn for our own meals. So, the government should start some job for HIV positive patients which should help us to earn our own bread."

THEME-6: Stigma among health care workers: Most of the HIV patients expressed that, they are not treated well in private hospitals.

One patient said that;

"When I had fever, and went to one private hospital, they were not ready to examine me rather than they gave me a medicine and send me away."

Another patient added to this;

"Once I approached a private hospital with severe sickness, my condition was very bad, that time I couldn't even speak. Despite of my sufferings, the healthcare workers were not ready to give me one injection even after my request and I was forced to come out of the hospital without treatment."

\section{Discussion}

The present study has provided an opportunity to the researcher to know the life experiences of HIV positive patients. Majority of patients expressed that, to get HIV their spouses only are responsible. This may be due to lack of intimacy and commitment between husband and wife.

Most of the participants have reacted negatively to their HIV positive diagnosis by means of fear, shock and inability to express. In addition to this few patients were feared to disclose their disease condition with their parents, children and friends. This may be due to fear of rejection by the family and society. Further, patients of both gender expressed that their spouses take care of them with love and care since they also are suffering with HIV positive.

Another painful matter the researchers was observed is that, all HIV positive patients came from nuclear family, among them, most of them had small children who were also HIV positive.

All patients expressed that, Anti-Retroviral Therapy causes excessive hunger and tiresome. This makes unable to fulfill their hunger because of their financial status.

All the study participants expressed that, to take care of themselves and their family, they require to work but the society is not able to accept them as it is and provide job. Hence, they requested the researchers to communicate to the government the same, so that the Government can plan a project where these HIV positive patients can work and earn for their own bread within their limitations.

Majority of patients expressed that, when they have visited to private hospitals, the health care workers were unable to treat them because of the stigma that still exist. This makes them not to go again for treatment which may cause to lose their life.

\section{Limitations}

The study was limited to HIV positive patients who were admitted at Samagra Community health center, a voluntary health organization and taking treatment at ART centre of SNR Government District Hospital, Kolar.

\section{Conclusion}

The study concluded that patients living with HIV positive are finding difficult to lead a life in day to day activities in terms that they were financially weak and unable to meet their daily bread, social stigma was one of the drawback to get job recruitment and reduced will power and energy level to survive further.

\section{Acknowledgment}

We wish to express our sincere gratitude to all HIV positive patients who participated in the study for their co-operation. Our heartfelt thanks to co-ordinator of Samagra community centre, SNR District hospital for giving permission to conduct a study. 


\section{References}

1 No authors listed (1998) Development of the World Health Organization WHOQOL-BREF quality of life assessment. The WHOQOL Group. Psychol Med 28: 551-558.

2 Clayson DJ, Wild DJ, Quarterman P, Duprat-Lomon I, Kubin M, et al. (2006) A comparative review of health-related quality of life measures for use in HIV/AIDS clinical trials. Pharmacoeconomics 24: 751-765.

3 Fauci AS (1999) The AIDS epidemic: Considerations for the $21^{\text {st }}$ Century. N Engl J Med 341: 1046-1050.

4 Walker N, Grassly NC, Garnett GP, Stanecki KA, Ghys PD (2004) Estimating the global burden of HIV/AIDS: What do we really know about the HIV pandemic? Lancet 363: 2180-2185.
5 Beck EJ, Miners AH, Tolley K (2001) The cost of HIV treatment and care: A global review. Pharmacoeconomics 19: 13-39.

6 Halloran J (2006) Increasing survival with HIV: Impact on nursing care. AACN Clin Issues 17: 8-17.

7 Kassutto S, Maghsoudi K, Johnston MN, Robbins GK, Burgett NC, et al. (2006) Longitudinal analysis of clinical markers following antiretroviral therapy initiated during acute or early HIV Type I infection. Clin Infect Dis 42: 1024-1031.

8 Aranda-Naranjo B (2004) Quality of life in HIV-positive patient. J Assoc Nurses AIDS Care 15: 20-27.

9 Hays RD, Cunningham WE, Sherbourne CD, Wilson IB, Wu AW, et al. (2000) Health-related quality of life in patients with human immunodeficiency virus infection in the United States: Results from the HIV Cost and Services Utilization Study. Am J Med 108: 714-722. 